International Journal of Pure and Applied Mathematics

Volume 92 No. 4 2014, 513-523

ISSN: 1311-8080 (printed version); ISSN: 1314-3395 (on-line version)

url: http://www.ijpam.eu

doi: http://dx.doi.org/10.12732/ijpam.v92i4.6

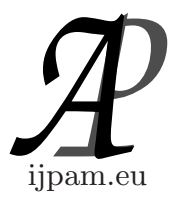

\title{
THREE BEST PROXIMITY POINT THEOREMS OF SOME GENERALIZED PROXIMAL CONTRACTIONS
}

\author{
Pinya Ardsalee ${ }^{1}$, Satit Saejung ${ }^{2} \S$ \\ ${ }^{1,2}$ Department of Mathematics \\ Faculty of Science \\ Khon Kaen University \\ Khon Kaen, 40002, THAILAND \\ ${ }^{2}$ The Centre of Excellence in Mathematics \\ Commission on Higher Education (CHE) \\ Sri Ayudthaya Road, Bangkok 10400, THAILAND
}

\begin{abstract}
We prove three best proximity point theorems by using the concept of contractive conditions introduced by Boyd and Wong. These results are generalizations of the corresponding ones recently proved by Sadiq Basha, Fernádez-León, and Sankar Raj.
\end{abstract}

AMS Subject Classification: 47H09, 47H10

Key Words: best proximity point, generalized contraction condition

\section{Introduction}

Let $A$ and $B$ be nonempty subsets of a metric space $(X, d)$ and $T: A \rightarrow B$ be a mapping. The problem of finding a best proximity point of $T$ is to find a point $x \in A$ such that $d(x, T x)=\inf \{d(a, b): a \in A, b \in B\}:=d(A, B)$. In particular, if $d(A, B)=0$, then a best proximity point of $T$ is nothing but a fixed point of $T$.

Received: November 15, 2013

(C) 2014 Academic Publications, Ltd.

${ }^{\S}$ Correspondence author url: www.acadpubl.eu 
In the same way as the study and development of fixed point theory, the theory of best proximity points have been extensively investigated (see $[1,2,3$, $6,7,8,9,10,11,12,14,15,16])$.

In the literature, many best proximity point theorems have been proposed from various approaches. To ensure the existence of a best proximity point, some certain conditions are imposed on mappings $T$ and on the sets $A$ and $B$.

In this paper, we consider the problem of finding a best proximity point of $T: A \rightarrow B$ with respect to a mapping $g: A \rightarrow A$, that is, we find a point $x \in A$ such that

$$
d(g x, T x)=d(A, B) .
$$

Obviously, if $g$ is the identity mapping, then this problem reduces to the original problem. Our results are inspired by the results in [5] and [13]. We study the very general contraction condition introduced by Boyd and Wong [4]. Hence we simultaneously generalize the corresponding theorems of Fernádez-León [5] and of Basha [13]. Moreover, we also obtain the recent result of Sankar Raj [6]. Let us summarize here their results. Recall that

$$
\begin{aligned}
& A_{0}:=\{x \in A: d(x, y)=d(A, B) \text { for some } y \in B\}, \\
& B_{0}:=\{y \in B: d(x, y)=d(A, B) \text { for some } x \in A\} .
\end{aligned}
$$

Theorem 1 ([5, Theorem 3.1]). Let $A$ and $B$ be nonempty subsets of a complete metric space $(X, d)$ such that $A_{0}$ is nonempty and let $T: A \rightarrow B$ and $g: A \rightarrow A$ be two mappings. Let us assume the following conditions:

(C1) $g$ is an isometry;

(C2) $A_{0} \subset g\left(A_{0}\right)$;

(C3) $T\left(A_{0}\right) \subset B_{0}$;

(C4a) $T$ is a proximal contraction of the first kind, that is, there is $\alpha \in[0,1)$ such that for all $u, v, x, y \in A$

$$
\left.\begin{array}{l}
d(u, T x)=d(A, B) \\
d(v, T y)=d(A, B)
\end{array}\right\} \Rightarrow d(u, v) \leq \alpha d(x, y)
$$

(C5a) $A_{0}$ is closed.

Then the followings hold:

1. There is a unique element $x$ in $A$ such that $d(g x, T x)=d(A, B)$; 
2. For each $x_{0} \in A_{0}$, the iterative sequence $\left\{x_{n}\right\}$ in $A_{0}$ defined by $d\left(g x_{n+1}\right.$, $\left.T x_{n}\right)=d(A, B)$ converges to $x$.

Theorem 2 ( [5, Theorem 3.7]). Let $A$ and $B$ be nonempty subsets of a complete metric space $(X, d)$ such that $A_{0}$ is nonempty and let $T: A \rightarrow B$ and $g: A \rightarrow A$ be two mappings. Let us assume the following conditions: (C1), (C2), (C3),

(C4b) $T$ is a proximal contraction of the second kind, that is, there is $\alpha \in[0, \infty)$ such that for all $u, v, x, y \in A$

$$
\left.\begin{array}{l}
d(u, T x)=d(A, B) \\
d(v, T y)=d(A, B)
\end{array}\right\} \Rightarrow d(T u, T v) \leq \alpha d(T x, T y)
$$

and preserves isometric distance with respect to $g$, that is, for all $x, y \in A$

$$
d(T(g x), T(g y))=d(T x, T y) ;
$$

(C5b) $T\left(A_{0}\right)$ is closed.

Then the followings hold:

1. There exists $x \in A$ such that $d(g x, T x)=d(A, B)$;

2. If there is another element $\widehat{x} \in A$ such that $d(g \widehat{x}, T \widehat{x})=d(A, B)$, then $T x=T \widehat{x}$.

Theorem 3 ([13, Theorem 3.6]). Let $A$ and $B$ be nonempty subsets of a complete metric space $(X, d)$ such that $A_{0}$ is nonempty and let $T: A \rightarrow B$ and $g: A \rightarrow A$ be two mappings. Let us assume the following conditions: (C1), (C2), (C3),

(C4c) $T$ is a generalized proximal contraction of the first kind, that is, for all $u, v, x, y \in A$

$$
\left.\begin{array}{l}
d(u, T x)=d(A, B) \\
d(v, T y)=d(A, B)
\end{array}\right\} \Rightarrow d(u, v) \leq d(x, y)-\varphi(d(x, y))
$$

where $\varphi:[0, \infty) \rightarrow[0, \infty)$ is continuous and nondecreasing such that $\varphi$ vanishes only at zero, and $\lim _{t \rightarrow \infty} \varphi(t)=\infty$;

(C5c) $A, B$ are closed and $B$ is approximatively compact with respect to $A$, that is, every sequence $y_{n}$ of $B$ satisfying the condition that $d\left(x, y_{n}\right) \rightarrow d(x, B)$ $(:=\inf \{d(x, w): w \in B\})$ for some $x$ in $A$ has a convergent subsequence. 
Then the followings hold:

1. There is a unique element $x$ in $A$ such that $d(g x, T x)=d(A, B)$;

2. For each $x_{0} \in A_{0}$, the iterative sequence $\left\{x_{n}\right\}$ in $A_{0}$ defined by $d\left(g x_{n+1}\right.$, $\left.T x_{n}\right)=d(A, B)$ converges to $x$.

Theorem 4 ([13, Theorem 3.1]). Let $A$ and $B$ be nonempty subsets of a complete metric space $(X, d)$ such that $A_{0}$ is nonempty and let $T: A \rightarrow B$ and $g: A \rightarrow A$ be two mappings. Let us assume the following conditions: (C1), (C2), (C3),

(C4d) $T$ is a generalized proximal contraction of the first kind (see Theorem 3) and it is a generalized proximal contraction of the second kind, that is, for all $u, v, x, y \in A$

$$
\left.\begin{array}{l}
d(u, T x)=d(A, B) \\
d(v, T y)=d(A, B)
\end{array}\right\} \Rightarrow d(T u, T v) \leq d(T x, T y)-\varphi(d(T x, T y))
$$

where $\varphi:[0, \infty) \rightarrow[0, \infty)$ is continuous and nondecreasing such that $\varphi$ vanishes only at zero, and $\lim _{t \rightarrow \infty} \varphi(t)=\infty$ and $T$ preserves the isometry distance with respect to $g$;

(C5d) $A, B$ are closed.

Then the followings hold:

1. There is a unique element $x$ in $A$ such that $d(g x, T x)=d(A, B)$;

2. For each $x_{0} \in A_{0}$, the iterative sequence $\left\{x_{n}\right\}$ in $A_{0}$ defined by $d\left(g x_{n+1}\right.$, $\left.T x_{n}\right)=d(A, B)$ converges to $x$.

\section{Main Result}

In this section, we assume that $A$ and $B$ are nonempty subsets of a metric space $(X, d)$ and $\psi:[0, \infty) \rightarrow[0, \infty)$ is upper semicontinuous from the right, $\psi(t)<t$ for all $t>0$ and $\psi(0)=0$. We use the following notations throughout this paper:

$$
\begin{aligned}
d(A, B) & :=\inf \{d(x, y): x \in A \text { and } y \in B\}, \\
A_{0} & :=\{x \in A: d(x, y)=d(A, B) \text { for some } y \in B\}, \\
B_{0} & :=\{y \in B: d(x, y)=d(A, B) \text { for some } x \in A\} .
\end{aligned}
$$


Definition 5. A mapping $T: A \rightarrow B$ is said to be

- a Boyd-Wong proximal contraction of the first kind (BW1, for short) if, for all $u, v, x, y \in A$,

$$
\left.\begin{array}{l}
d(u, T x)=d(A, B) \\
d(v, T y)=d(A, B)
\end{array}\right\} \Rightarrow d(u, v) \leq \psi(d(x, y))
$$

- a Boyd-Wong proximal contraction of the second kind (BW2) if, for all $u, v, x, y \in A$,

$$
\left.\begin{array}{l}
d(u, T x)=d(A, B) \\
d(v, T y)=d(A, B)
\end{array}\right\} \Rightarrow d(T u, T v) \leq \psi(d(T x, T y)) .
$$

Lemma 6. Let $A$ and $B$ be nonempty subsets of a metric space $(X, d)$. Let $T: A \rightarrow B$ and $g: A \rightarrow A$ be mappings such that $g$ is an isometry. Assume that there exist $x, y \in A$ such that $d(g x, T x)=d(g y, T y)=d(A, B)$. Then the followings hold:

(1) If $T$ is a $B W 1$, then $y=x$;

(2) If $T$ is a $B W 2$ and preserves the isometry distance with respect to $g$, then $T y=T x$.

Proof. (1) Let us assume that $T$ is a BW1. It follows from the isometry of $g$ and the definition of BW1

$$
d(x, y)=d(g x, g y) \leq \psi(d(x, y)) .
$$

Since $\psi(t)<t$ for all $t>0$, we have $d(x, y)=0$, that is, $x=y$.

(2) Let us assume that $T$ is a BW2 and preserves the isometry distance with respect to $g$. By assumption, we obtain

$$
d(T x, T y)=d(T(g x), T(g y)) \leq \psi(d(T x, T y)) .
$$

Since $\psi(t)<t$ for all $t>0$, we have $d(T x, T y)=0$, that is, $T x=T y$.

Lemma 7. Let $A$ and $B$ be nonempty subsets of a metric space $(X, d)$ such that $A_{0}$ is nonempty. Let $T: A \rightarrow B$ be a mapping such that $T\left(A_{0}\right) \subset B_{0}$ and

$$
\left.\begin{array}{l}
d(u, T x)=d(A, B) \\
d(v, T y)=d(A, B)
\end{array}\right\} \Rightarrow d(u, v) \leq d(x, y)
$$

where $u, v, x, y \in A$. Let $g: A \rightarrow A$ be an isometry such that $A_{0} \subset g\left(A_{0}\right)$. Then the followings hold: 
(1) For a fixed element $x_{0} \in A_{0}$, we can construct an iterative sequence $\left\{x_{n}\right\} \subset A_{0}$ such that $d\left(g x_{n+1}, T x_{n}\right)=d(A, B)$ for each $n \geq 0$;

(2) If $x_{n} \rightarrow x$ for some $x \in A_{0}$, then $d(g x, T x)=d(A, B)$;

(3) If $x_{n} \rightarrow x$ for some $x \in A$ and there exists a sequence $\left\{n_{k}\right\} \subset\{n\}$ such that $T x_{n_{k}} \rightarrow y$ for some $y \in B$, then $x \in A_{0}$ and hence $d(g x, T x)=d(A, B)$.

Proof. (1) Let $x_{0} \in A_{0}$. Since $T\left(A_{0}\right) \subset B_{0}$ and $A_{0} \subset g\left(A_{0}\right)$, there is $x_{1} \in A_{0}$ such that $d\left(g x_{1}, T x_{0}\right)=d(A, B)$. By induction, we obtain a sequence $\left\{x_{n}\right\} \subset A_{0}$ such that $d\left(g x_{n+1}, T x_{n}\right)=d(A, B)$ for all $n \geq 0$.

(2) We assume that $x_{n} \rightarrow x$ for some $x \in A_{0}$. Since $T x \in T\left(A_{0}\right) \subset B_{0}$ and $A_{0} \subset g\left(A_{0}\right)$, there exists $z \in A_{0}$ such that $d(g z, T x)=d(A, B)$. By the property of $T$, we have $d\left(g z, g x_{n+1}\right) \leq d\left(x, x_{n}\right)$. Since $g$ is an isometry, $d\left(g z, g x_{n+1}\right)=d\left(z, x_{n+1}\right)$. Hence for each $n \geq 1$,

$$
d\left(z, x_{n+1}\right) \leq d\left(x, x_{n}\right)
$$

As $n \rightarrow \infty$, we obtain that $x_{n+1} \rightarrow z$ and hence $z=x$. This implies that $d(g x, T x)=d(A, B)$.

(3) We assume that $x_{n} \rightarrow x$ for some $x \in A$ and there exists a sequence $\left\{n_{k}\right\} \subset\{n\}$ such that $T x_{n_{k}} \rightarrow y$ for some $y \in B$. Since $g$ is an isometry, we have $g x_{n_{k}+1} \rightarrow g x$. So we obtain

$$
d(g x, y)=\lim _{k \rightarrow \infty} d\left(g x_{n_{k}+1}, T x_{n_{k}}\right)=d(A, B) .
$$

Therefore $g x \in A_{0}$. Since $g x \in A_{0} \subset g\left(A_{0}\right)$, there is $z \in A_{0}$ such that $g z=g x$. In particular, $d(x, z)=d(g x, g z)=0$. Hence $x=z \in A_{0}$.

We are now ready to prove our first main result for BW1.

Theorem 8. Let $A$ and $B$ be nonempty subsets of a complete metric space $(X, d)$ such that $A_{0}$ is nonempty and let $T: A \rightarrow B$ and $g: A \rightarrow A$ be two mappings. Let us assume the following conditions: (C1), (C2), (C3),

(C4e) $T$ is a $B W 1$;

(C5a) $A_{0}$ is closed.

Then the followings hold:

1. There is a unique element $x$ in $A$ such that $d(g x, T x)=d(A, B)$;

2. For each $x_{0} \in A_{0}$, the iterative sequence $\left\{x_{n}\right\}$ in $A_{0}$ defined by $d\left(g x_{n+1}\right.$, $\left.T x_{n}\right)=d(A, B)$ converges to $x$. 
Proof. Let $x_{0} \in A_{0}$. By Lemma 7 (1), we obtain a sequence $\left\{x_{n}\right\} \subset A_{0}$ such that

$$
d\left(g x_{n+1}, T x_{n}\right)=d(A, B)
$$

for all $n \geq 0$. Put $c_{n}:=d\left(x_{n}, x_{n-1}\right)$. Due to $(\mathrm{C} 1)$ and $(\mathrm{C} 4)$, we get

$$
c_{n+1}=d\left(x_{n+1}, x_{n}\right)=d\left(g x_{n+1}, g x_{n}\right) \leq \psi\left(d\left(x_{n}, x_{n-1}\right)\right) \leq d\left(x_{n}, x_{n-1}\right)=c_{n}
$$

for all $n \in \mathbb{N}$. So $c_{n} \rightarrow c^{+}$for some $c \geq 0$. To show that $c=0$, we suppose that $c>0$. Since $c_{n+1} \leq \psi\left(c_{n}\right)$ for all $n \in \mathbb{N}$,

$$
c \leq \limsup _{n \rightarrow \infty} \psi\left(c_{n}\right) \leq \psi(c)<c
$$

which is a contradiction. So $c=0$.

Claim: $\left\{x_{n}\right\}$ is a Cauchy sequence. Otherwise, there exist $\varepsilon>0$ and two sequences $\left\{m_{k}\right\}$ and $\left\{n_{k}\right\}$ such that

- $m_{k}>n_{k} \geq k$

- $d\left(x_{m_{k}-1}, x_{n_{k}}\right)<\varepsilon \leq d\left(x_{m_{k}}, x_{n_{k}}\right)$

for all $k \in \mathbb{N}$. Put $d_{k}:=d\left(x_{m_{k}}, x_{n_{k}}\right)$. Then

$$
\varepsilon \leq d_{k} \leq d\left(x_{m_{k}}, x_{m_{k}-1}\right)+d\left(x_{m_{k}-1}, x_{n_{k}}\right) \leq c_{m_{k}}+\varepsilon
$$

for all $k \in \mathbb{N}$. So $d_{k} \rightarrow \varepsilon^{+}$and hence $\lim \sup _{k \rightarrow \infty} \psi\left(d_{k}\right) \leq \psi(\varepsilon)$. Furthermore, since

$$
\begin{aligned}
d_{k}=d\left(x_{m_{k}}, x_{n_{k}}\right) & \leq d\left(x_{m_{k}}, x_{m_{k}+1}\right)+d\left(x_{m_{k}+1}, x_{n_{k}+1}\right)+d\left(x_{n_{k}+1}, x_{n_{k}}\right) \\
& =c_{m_{k}+1}+d\left(g x_{m_{k}+1}, g x_{n_{k}+1}\right)+c_{n_{k}+1} \\
& \leq c_{m_{k}+1}+\psi\left(d\left(x_{m_{k}}, x_{n_{k}}\right)\right)+c_{n_{k}+1},
\end{aligned}
$$

we have

$$
\varepsilon=\limsup _{k \rightarrow \infty} d_{k} \leq \limsup _{k \rightarrow \infty}\left(c_{m_{k}+1}+\psi\left(d_{k}\right)+c_{n_{k}+1}\right) \leq \psi(\varepsilon)<\varepsilon
$$

which is a contradiction. Hence $\left\{x_{n}\right\}$ is a Cauchy sequence in $A_{0}$. So we have the claim.

Because $\left\{x_{n}\right\}$ is a Cauchy sequence in $A_{0}$ and (C5) holds, so we may assume that $x_{n} \rightarrow x$ for some $x \in A_{0}$. By Lemma $7(2)$, we obtain $d(g x, T x)=d(A, B)$. For the uniqueness, it follows from Lemma 6 (1). 
Remark 9. 1. Theorem 3.1 of [5] (see Theorem 1) follows from our Theorem 8 if we set $\psi(t)=\alpha t$ for all $t \in[0, \infty)$.

2. Theorem 3.6 of [13] (see Theorem 3) follows from our Theorem 8 if we set $\psi(t)=t-\varphi(t)$ for all $t \in[0, \infty)$. Furthermore, it is assumed there that $B$ is approximatively compact with respect to $A$. As mentioned in [5], if $A$ and $B$ are closed and $B$ is approximatively compact with respect to $A$, then $A_{0}$ is closed.

Remark 10. The conclusion of Theorem 8 remains true if we assume that $T$ is continuous and $A$ is closed in place of (C5). Hence we can deduce the recent result of Sankar Raj (see [6, Theorem 3.1]). In fact, the weak contraction in sense of Sankar Raj and the P-property imply BW1. It is noted that, in general, BW1 does not imply the continuity (see [5, Example 2.6]).

Next, we prove our second main result for BW2.

Theorem 11. Let $A$ and $B$ be nonempty subsets of a complete metric space $(X, d)$ such that $A_{0}$ is nonempty and let $T: A \rightarrow B$ and $g: A \rightarrow A$ be two mappings. Let us assume the following conditions: (C1), (C2), (C3),

(C4f) $T$ is a $B W 2$ and preserves isometric distance with respect to $g$;

(C5b) $T\left(A_{0}\right)$ is closed.

Then the followings hold:

1. There exists $x \in A$ such that $d(g x, T x)=d(A, B)$.

2. If there is another element $\widehat{x} \in A$ such that $d(g \widehat{x}, T \widehat{x})=d(A, B)$, then $T x=T \widehat{x}$.

Proof. Let $x_{0} \in A_{0}$. By Lemma 7 (1), we get a sequence $\left\{x_{n}\right\} \subset A_{0}$ such that

$$
d\left(g x_{n+1}, T x_{n}\right)=d(A, B)
$$

for all $n \geq 0$. Put $e_{n}:=d\left(T x_{n}, T x_{n-1}\right)$. By $\left(\mathrm{C} 4^{*}\right)$, we have

$$
d\left(T x_{n+1}, T x_{n}\right)=d\left(T\left(g x_{n+1}\right), T\left(g x_{n}\right)\right) \leq \psi\left(d\left(T x_{n}, T x_{n-1}\right)\right) \leq d\left(T x_{n}, T x_{n-1}\right)
$$

for all $n \in \mathbb{N}$. So we get $e_{n} \rightarrow e^{+}$for some $e \geq 0$. To show that $e=0$, we suppose $e>0$. Since $e_{n+1} \leq \psi\left(e_{n}\right)$ for each $n \in \mathbb{N}$,

$$
e \leq \limsup _{n \rightarrow \infty} \psi\left(e_{n}\right) \leq \psi(e)<e
$$


which is a contradiction. Hence $e=0$.

Claim: $\left\{T x_{n}\right\}$ is a Cauchy sequence. Otherwise, there exist $\varepsilon>0$ and two sequences $\left\{m_{k}\right\}$ and $\left\{n_{k}\right\}$ such that

- $m_{k}>n_{k} \geq k$

- $d\left(T x_{m_{k}-1}, T x_{n_{k}}\right)<\varepsilon \leq d\left(T x_{m_{k}}, T x_{n_{k}}\right)$

for all $k \in \mathbb{N}$. Put $f_{k}:=d\left(T x_{m_{k}}, T x_{n_{k}}\right)$. Then

$$
\varepsilon \leq f_{k} \leq d\left(T x_{m_{k}}, T x_{m_{k}-1}\right)+d\left(T x_{m_{k}-1}, T x_{n_{k}}\right) \leq e_{m_{k}}+\varepsilon
$$

for all $k \in \mathbb{N}$. So $f_{k} \rightarrow \varepsilon^{+}$and hence $\lim \sup _{k \rightarrow \infty} \psi\left(f_{k}\right) \leq \psi(\varepsilon)$. Furthermore, since

$$
\begin{aligned}
f_{k}=d\left(T x_{m_{k}}, T x_{n_{k}}\right) \leq & d\left(T x_{m_{k}}, T x_{m_{k}+1}\right)+d\left(T x_{m_{k}+1}, T x_{n_{k}+1}\right) \\
& +d\left(T x_{n_{k}+1}, T x_{n_{k}}\right) \\
= & e_{m_{k}+1}+d\left(T\left(g x_{m_{k}+1}\right), T\left(g x_{n_{k}+1}\right)\right)+e_{n_{k}+1} \\
\leq & e_{m_{k}+1}+\psi\left(d\left(T x_{m_{k}}, T x_{n_{k}}\right)\right)+e_{n_{k}+1}
\end{aligned}
$$

we have

$$
\varepsilon=\limsup _{k \rightarrow \infty} f_{k} \leq \limsup _{k \rightarrow \infty} \psi\left(e_{m_{k}+1}+\psi\left(d\left(T x_{m_{k}}, T x_{n_{k}}\right)\right)+e_{n_{k}+1}\right) \leq \psi(\varepsilon)<\varepsilon
$$

which is a contradiction. Therefore we obtain that $\left\{T x_{n}\right\}$ is a Cauchy sequence in $T\left(A_{0}\right)$. Hence we have the claim.

Since $T\left(A_{0}\right)$ is closed, we get $T x_{n} \rightarrow T u$ for some $u \in A_{0}$. By $(\mathrm{C} 2)$ and (C3), there is $x \in A_{0}$ such that $d(g x, T u)=d(A, B)$. Consider

$$
d\left(T x, T x_{n+1}\right)=d\left(T(g x), T\left(g x_{n+1}\right)\right) \leq \psi\left(d\left(T u, T x_{n}\right)\right) \leq d\left(T u, T x_{n}\right)
$$

for all $n \in \mathbb{N}$. As $n \rightarrow \infty$, we obtain $T x=T u$. Thus $d(g x, T x)=d(A, B)$. The conclusion (2) follows from Lemma 6 (2).

We finally discuss the result whenever $T$ is simultaneously a BW1 and a BW2. It is shown below that we need neither (C5a) of Theorem 8 nor (C5b) of Theorem 11 in this situation. As mentioned in Remark 9, the following conditions $(\mathrm{C} 4 \mathrm{e})$ and $(\mathrm{C} 4 \mathrm{f})$ are weaker than $(\mathrm{C} 4 \mathrm{~d})$ and this implies that our Theorem 12 is a generalization of Theorem 4 .

Theorem 12. Let $A$ and $B$ be nonempty subsets of a complete metric space $(X, d)$ such that $A_{0}$ is nonempty. Let $T: A \rightarrow B$ and $g: A \rightarrow A$ satisfy the following conditions: $(\mathrm{C} 1),(\mathrm{C} 2),(\mathrm{C} 3),(\mathrm{C} 4 \mathrm{e}),(\mathrm{C} 4 \mathrm{f})$, 
(C5d) $A, B$ are closed.

Then the followings hold:

1. There exists a unique element $x \in A$ such that $d(g x, T x)=d(A, B)$;

2. For any fixed $x_{0} \in A_{0}$, the iterative sequence $\left\{x_{n}\right\}$ defined by $d\left(g x_{n+1}\right.$, $\left.T x_{n}\right)=d(A, B)$ converges to $x$.

Proof. By Lemma 7 (1), we get a sequence $\left\{x_{n}\right\} \subset A_{0}$ such that

$$
d\left(g x_{n+1}, T x_{n}\right)=d(A, B)
$$

for all $n \geq 0$. By following the proof of Theorem 8 and 11, we obtain that $\left\{x_{n}\right\}$ and $\left\{T x_{n}\right\}$ are Cauchy sequences. So we may assume that $x_{n} \rightarrow x$ for some $x \in A$ and $T x_{n} \rightarrow y$ for some $y \in B$. By Lemma 7 (2) and (3), we get $d(g x, T x)=d(A, B)$. The uniqueness follows from Lemma 6 (1).

\section{Acknowledgments}

The first author is thankful to the Development and Promotion of Science and Technology Talents Project (DPST) for financial support. The second and third authors are supported by the Centre of Excellence in Mathematics, the office of Commission on Higher Education of Thailand.

\section{References}

[1] A. Anthony Eldred, W.A. Kirk, P. Veeramani, Proximal normal structure and relatively nonexpansive mappings, Studia Math., 171, No. 3 (2005), 283-293, doi: 10.4064/sm171-3-5.

[2] J. Anuradha, P. Veeramani, Proximal pointwise contraction, Topology Appl., 156, No. 18 (2009), 2942-2948, doi: 10.1016/j.topol.2009.01.017.

[3] C.D. Bari, T. Suzuki, C. Vetro, Best proximity points for cyclic MeirKeeler contractions, Nonlinear Anal., 69, No. 11 (2008), 3790-3794, doi: 10.1016/j.na.2007.10.014.

[4] D.W. Boyd, J.S.W. Wong, On nonlinear contractions, Proc. Amer. Math. Soc., 20, (1969), 458-464. 
[5] A. Fernádez-León, Best proximity points for proximal contractions, Journal of Nonlinear and Convex Analysis, 15, No. 2 (2014), 313-324.

[6] V.S. Raj, A best proximity point theorem for weakly contractive nonself-mappings, Nonlinear Anal., 74, No. 14 (2011), 4804-4808, doi: 10.1016/j.na.2011.04.052.

[7] S. Sadiq Basha, Extensions of Banach's contraction principle, Numer. Funct. Anal. Optim., 31, No. 4-6 (2010), 569-576, doi: 10.1080/01630563.2010.485713.

[8] S. Sadiq Basha, Best proximity points: global optimal approximate solutions, J. Global Optim., 49, No. 1 (2011), 15-21, doi: 10.1007/s10898-0099521-0.

[9] S. Sadiq Basha, Best proximity points: optimal solutions, J. Optim. Theory Appl., 151, No. 1 (2011), 210-216, doi: 10.1007/s10957-011-9869-4.

[10] S. Sadiq Basha, Best proximity point theorems, Journal of Approximation Theory, 163, (2011), 17721781, doi: 10.1016/j.jat.2011.06.012.

[11] S. Sadiq Basha, Best proximity point theorems generalizing the contraction principle, Nonlinear Anal., 74, No. 17 (2011), 5844-5850, doi: 10.1016/j.na.2011.04.017.

[12] S. Sadiq Basha, Global optimal approximate solutions, Optim. Lett., 5, No. 4 (2011), 639-645, doi: 10.1007/s11590-010-0227-5.

[13] S. Sadiq Basha, Best proximity point theorems: an exploration of a common solution to approximation and optimization problems, Appl. Math. Comput., 218, No. 19 (2012), 9773-9780, doi: 10.1016/j.amc.2012.03.033.

[14] S. Sadiq Basha, Common best proximity points: global minimization of multi-objective functions, J. Global Optim., 54, No. 2 (2012), 367-373, doi: $10.1007 / \mathrm{s} 10898-011-9760-8$.

[15] S. Sadiq Basha, N. Shahzad, Best proximity point theorems for generalized proximal contractions, Fixed Point Theory Appl., 42, (2012), 9 pp, doi: 10.1186/1687-1812-2012-42.

[16] N. Shahzad, S. Sadiq Basha, R. Jeyaraj, Common best proximity points: global optimal solutions, J. Optim. Theory Appl., 148, No. 1 (2011), 69-78, doi: 10.1007/s10957-010-9745-7. 
